\title{
In vivo interpretation of model predicted inhibition in acrylate pathway engineered Lactococcus lactis
}

\author{
Sowmiya Balasubramanian ${ }^{1}$, Priyadharshini Chandrasekran ${ }^{1}$, Vijayalaksmi Kandasamy ${ }^{1}$, \\ Mark Eiteman ${ }^{2}$, and Ramalingam Subramanian ${ }^{1}$ \\ ${ }^{1}$ Anna University Chennai \\ ${ }^{2}$ University of Georgia
}

April 28, 2020

\begin{abstract}
In order to maximize the productivity of engineered metabolic pathway, in silico model is an established means to provide features of enzyme reaction dynamics. In our previous study, E.coli engineered with acrylate pathway yielded low propionic acid titre. To understand the bottleneck behind this low productivity, a kinetic model was developed that incorporates the enzymatic reactions of the acrylate pathway. The resulting model was capable of simulating the fluxes reported under in vitro studies with good agreement, suggesting repression of propionyl-CoA transferase by carboxylate metabolites as the main limiting factor for propionate production. Furthermore, the predicted flux control coefficients of the pathway enzymes under steady state conditions revealed that the control of flux is shared between propionyl-CoA transferase and lactoyl-CoA dehydratase. Increase in lactate concentration showed gradual decrease in flux control coefficients of propionyl-CoA transferase that in turn confirmed the control exerted by the carboxylate substrate. To interpret these in silico predictions under in vivo system, an organized study was conducted with a Lactic Acid Bacteria (LAB) strain engineered with acrylate pathway. Analysis reported a decreased product formation rate on attainment of inhibitory titre by suspected metabolites and supported the model.
\end{abstract}

\section{Hosted file}

Manuscript.doc available at https://authorea.com/users/303734/articles/433901-in-vivo-interpretationof-model-predicted-inhibition-in-acrylate-pathway-engineered-lactococcus-lactis

\section{Hosted file}

Figures.docx available at https://authorea.com/users/303734/articles/433901-in-vivo-interpretationof-model-predicted-inhibition-in-acrylate-pathway-engineered-lactococcus-lactis 